\title{
Article \\ Solvent-Free Benzylation of Glycerol by Benzyl Alcohol Using Heteropoly Acid Impregnated on K-10 Clay as Catalyst
}

\author{
Devendra P. Tekale ${ }^{1} \oplus$, Ganapati D. Yadav ${ }^{1, *}$ and Ajay K. Dalai ${ }^{2}$ \\ 1 Department of Chemical Engineering, Institute of Chemical Technology, Nathalal Parekh Marg, Matunga, \\ Mumbai 400019, India; ptdevendra11@gmail.com \\ 2 Catalysis and Chemical Reaction Engineering Laboratory, Department of Chemical \& Biological Engineering, \\ University of Saskatchewan, Saskatoon, SK S7N 5A9, Canada; ajay.dalai@usask.ca \\ * Correspondence: gd.yadav@ictmumbai.edu.in or gdyadav@yahoo.com; Tel.: +91-22-3361-1001 or \\ $+91-22-3361-1002 / 1020$
}

Citation: Tekale, D.P.; Yadav, G.D.; Dalai, A.K. Solvent-Free Benzylation of Glycerol by Benzyl Alcohol Using Heteropoly Acid Impregnated on K-10 Clay as Catalyst. Catalysts 2021, 11,34. https://doi.org/10.3390/ catal11010034

Received: 21 November 2020 Accepted: 25 December 2020 Published: 30 December 2020

Publisher's Note: MDPI stays neutral with regard to jurisdictional clai$\mathrm{ms}$ in published maps and institutional affiliations.

Copyright: (C) 2020 by the authors. Licensee MDPI, Basel, Switzerland. This article is an open access article distributed under the terms and conditions of the Creative Commons Attribution (CC BY) license (https:// creativecommons.org/licenses/by/ $4.0 /)$.

\begin{abstract}
Value addition to glycerol, the sole co-product in biodiesel production, will lead to reform of the overall biodiesel economy. Different valuable chemicals can be produced from glycerol using heterogeneous catalysis and these valuable chemicals are useful in industries such as cosmetics, pharmaceuticals, fuels, soap, paints, and fine chemicals. Therefore, the conversion of glycerol to valuable chemicals using heterogeneous catalysis is a noteworthy area of research. Etherification of glycerol with alkenes or alcohols is an important reaction in converting glycerol to various valueadded chemicals. This article describes reaction of glycerol with benzyl alcohol in solvent-free medium by using a clay supported modified heteropolyacid (HPA), $\mathrm{Cs}_{2.5} \mathrm{H}_{0.5} \mathrm{PW}_{12} \mathrm{O}_{40} / \mathrm{K}-10$ (Cs$\mathrm{DTP} / \mathrm{K}-10$ ) as solid catalyst and its comparison with other catalysts in a batch reactor. Mono-Benzyl glycerol ether (MBGE) was the major product formed in the reaction along with formation of $d i$-benzyl glycerol ether (DBGE). The effects of different parameters were studied to optimize the reaction parameters. This work provides an insight into characterization of $\mathrm{Cs}_{2.5} \mathrm{H}_{0.5} \mathrm{PW}_{12} \mathrm{O}_{40} / \mathrm{K}-10$ catalyst by advanced techniques such as surface area measurement, X-ray analysis, ICP-MS, FT-IR, and SEM. Reaction products were characterized and confirmed by using the GCMS method. The kinetic model was developed from an insight into the reaction mechanism. The apparent energy of activation was found to be $18.84 \mathrm{kcal} / \mathrm{mol}$.
\end{abstract}

Keywords: glycerol; benzylation; etherification; mono-benzyl glycerol ether; heteropolyacid

\section{Introduction}

The sustainability of raw materials is the major challenge for the chemical and allied industries [1]. Biodiesel, a popular term for the fatty acid methyl esters, is an alternative to fossil fuels. As reported by He and Yang in their review on renewable and sustainable energy, the global market of glycerol is predicted to grow up to USD 2.52 billion by end of 2020, and biodiesel is predicted as a leading source for the production of glycerol, with more than $1400 \mathrm{kt}$ production in the year 2017 [2]. As a result, glycerol production is climbing at an annual growth rate of $>50 \%$ [3]. Thus, bio glycerol offers an opportunity as a potential building block to produce a variety of valuable derivatives [4-8] which have further applications as fuel additives [9], cryogenics [10], and in detergent, pharmaceutical, food, and cosmetic industries. Some of these industries use glycerol and its ethers as green solvents [11]. Glycerol on reaction with either alcohols or alkenes produces ethers which are used as fuel additives [12]. In the present work etherification of glycerol was carried out using solid acid catalysts. Depending up on the reaction parameters mono-, $d i$ - or tri- ether of glycerol can be formed. Glycerol mono ethers are also called as 'solvosurfactants' owing to their dual characteristics of solvent as well as surfactant. Glycerol tert-butyl ethers are identified as alternate fuel additives to methyl tert-butyl ether (MTBE) in diesel and produced by etherifying glycerol with 2-butene or tert-butanol using acid 
catalysts $[13,14]$. Properties such as acid strength, distribution of hydrophilic and lipophilic sites, and surface porosity of the catalyst are important in controlling the progress of the etherification reaction [15]. Dominguez et al. studied glycerol etherification with tert-butanol by Amberlyst-15, a cation exchange resin catalyst leading to $96 \%$ glycerol conversion after $180 \mathrm{~min}$. at $90^{\circ} \mathrm{C}$ for tert-butanol to glycerol molar ratio of 4:1 [16]. Gu et al. reported use of $\mathrm{SO}_{3} \mathrm{H}$ catalysts to react glycerol with different alcohols such as benzyl alcohol, propargyl and allyl alcohols, olefins, to corresponding MAGEs in $60 \%$ to $90 \%$ yield [17]. Their method introduced a metal and salt free catalytic path for etherification of glycerol. Barrault et al. described $88 \%$ regioselective formation of $\alpha$-monoalkyl glycerol ether at $80{ }^{\circ} \mathrm{C}$ over acid treated silica $\left(\mathrm{SiO}_{2}-\mathrm{SO}_{3} \mathrm{H}\right)$ [18]. Some reports are available on glycerol benzylation using benzyl alcohol by homogeneous as well as heterogeneous solid acid catalysis.

The present work describes reaction of glycerol with benzyl alcohol using acid catalysts in a batch reactor. As shown in Scheme 1; mono-benzyl glycerol ether (MBGE) and di-benzyl glycerol ether (DBGE) were formed with $d i$-benzyl ether as the by-product by sequential reaction of MBGE. MBGE is used as surfactant and fuel additive. Products MBGE and DBGE are important intermediates used for synthesis of various valuable products. The amino derivative of MBGE is used as an $\alpha$ and $\beta$ adrenergic blocking agent while MBGE has application as an intermediate for the synthesis of anti-microbial active agents [19,20]. Many reactions of industrial practice are catalysed by acids which need to be replaced by solid acids and super acids to increase selectivity, process efficiency and for reducing the environmental footprint [21-39]. In this regard, heteropolyacids [21-25], acid treated clays [21,25], sulphated zirconia, and its modified versions including UDCaTs [26-33], supported heteropoly acids and particularly dodecatungstophopshoric acid (DTP) and cesium modified DTP on K-10 clay [34-39], and ion exchange resin [40] has been used for alkylation reactions. The other reactions include nitration, acylation, cracking, isomerization, oligomerization, and polymerisation, etc. Our research group has been at the forefront of designing, synthesis, characterization and application of such materials in a spectrum of chemical processes in the literature cited above. The above literature also showed that this cesium modified DTP on K-10 clay catalyst was found to be a stable and robust heterogeneous catalyst for wide range of types of acid catalysed unit operations and reaction conditions. This prompted and motivated us to undertake the study of efficacy and stability of this catalyst for glycerol benzylation.

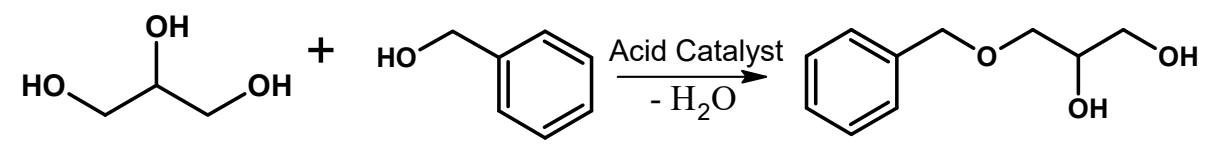

Glycerol
Benzyl alcohol 3-(benzyloxy)propane-1,2-diol

(MBGE)<smiles>OCC(O)COCc1ccccc1</smiles><smiles>OCc1ccc(-c2ccccc2)cc1</smiles>

(DBGE)

2<smiles>OCc1ccccc1</smiles><smiles>Oc1ccc(COCc2ccccc2)cc1</smiles>

Scheme 1. Reaction products for benzylation of glycerol with benzyl alcohol. 
The best catalyst, $20 \% w / w \mathrm{Cs}_{2.5} \mathrm{H}_{0.5} \mathrm{PW}_{12} \mathrm{O}_{40} / \mathrm{K}-10$, was physico-chemically studied by advanced analytical techniques, such as surface porosimetry, ICPMS, FT-IR, X-ray diffraction, and SEM. Products were confirmed by mass spectroscopic method. Characterization of fresh as well as used catalyst was conducted to study the morphological and chemical changes in the catalyst during the reaction.

\section{Result and Discussion}

\subsection{Efficacy of Differrent Catalysts}

A series of solid acid catalysts was assessed to study their efficacy for benzylation of glycerol. Commercially available catalyst Amberlyst-15 was used along with 20\% w/w DTP/K-10 and UDCaT-4 to evaluate their efficacy. Figure 1 compares the performance of $20 \% w / w \mathrm{Cs}_{2.5} \mathrm{H}_{0.5} \mathrm{PW}_{12} \mathrm{O}_{40} / \mathrm{K}-10$, Amberlyst-15, 20\% $w / w$ DTP/K-10, and UDCaT-4 catalysts. The purpose of screening a series of solid acid catalysts was to understand the effect of surface morphology, acid strength, and pore size distribution on glycerol conversion and its effect on selectivity towards MBGE. All these catalysts were screened at $150{ }^{\circ} \mathrm{C}, 1: 3$ glycerol to benzyl alcohol mole ratio for $4 \mathrm{~h}$ with $0.03 \mathrm{~g} / \mathrm{cm}^{3}$ loading of catalyst. It was found that $20 \% w / w \mathrm{Cs}_{2.5} \mathrm{H}_{0.5} \mathrm{PW}_{12} \mathrm{O}_{40} / \mathrm{K}-10$ clay showed maximum (48\%) conversion of glycerol with $76 \%$ selectivity for MBGE. The mass spectra of the MBGE (Figure S1) and DBGE (Figure S2) are enclosed as Supplementary Material.

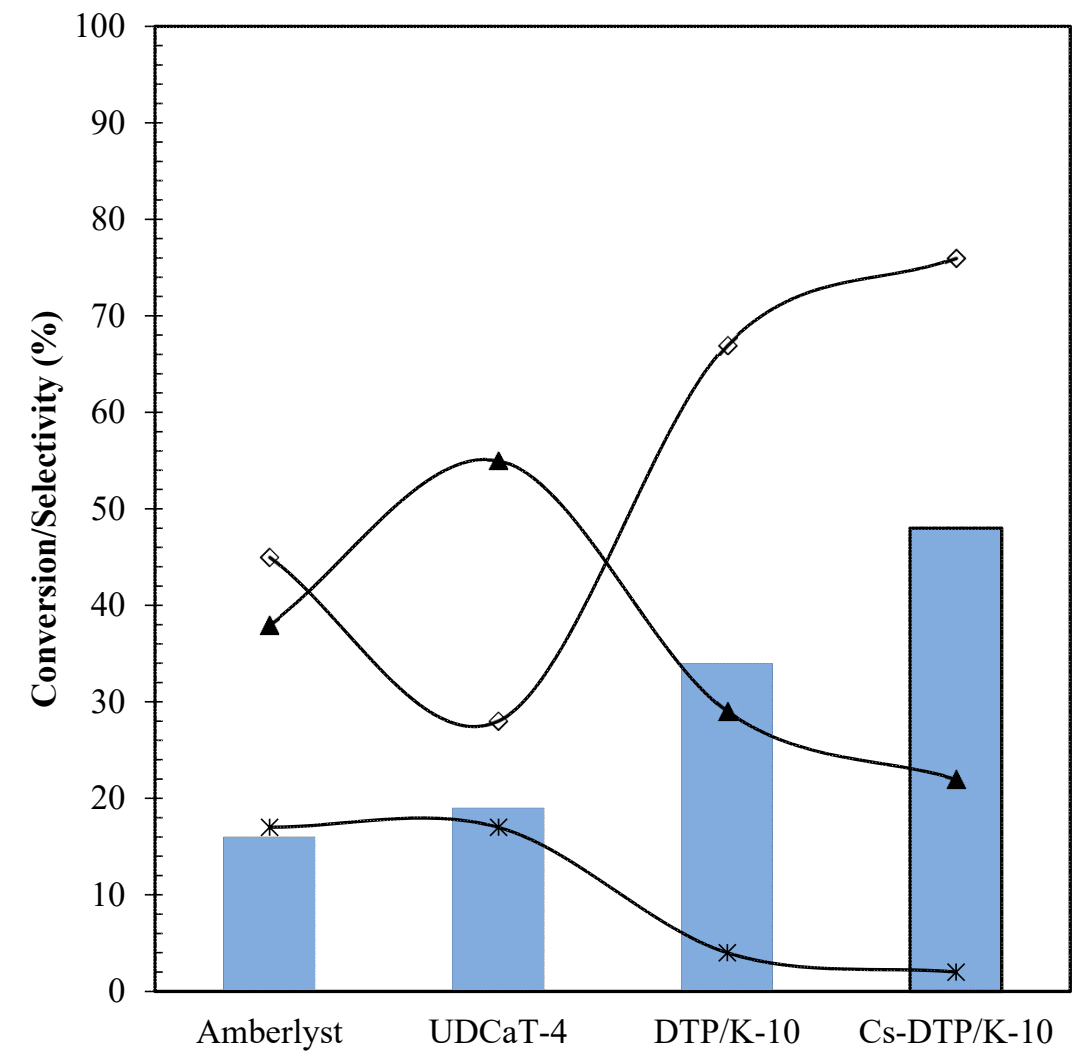

Figure 1. Efficacy of different catalysts. Temperature: $150^{\circ} \mathrm{C}$. Catalyst loading: $0.03 \mathrm{~g} / \mathrm{cm}^{3}$. Glycerol:BA mole ratio $=1: 3$, speed of agitation: $1000 \mathrm{rpm}$, reaction time: $4 \mathrm{~h}$.

\subsection{Product Profile}

The published literature shows different product distribution as a result of type of catalyst and various reaction parameters for different solid acid catalysts. $\beta$-Zeolite and Amberlyst-35 gave MBGE as the main product whereas when $p$-toluenesulfonic acid (PTSA) 
and K-10 montmorillonite clay were used as catalyst; the product di-benzyl ether was found in higher yield [41]. Reaction temperature has predominant effect on product distribution and course of reaction. Nature of catalyst support plays deciding role in controlling the reaction equilibrium by shifting it in forward direction as seen in montmorillonite clay by adsorbing the water of reaction formed during the course of the reaction. In the present study MBGE was the main product formed with 76\% selectivity. Mono-benzyl glycerol ether and di-benzyl glycerol ether were extracted in ethyl acetate and were further isolated by column chromatography in hexane and ethyl acetate phase. The purified compound diluted in methanol and injected for direct mass analysis using +ve ESI (Electron Spray Ionisation) mode. The distinct peak at m/z 205 confirms the molecular ion peak $\left(\mathrm{M}^{+}\right)+23$; whereas molecular weight for mono-benzyl glycerol ether is $182 \mathrm{~m} / \mathrm{z}$. The peak at $\mathrm{m} / \mathrm{z} 295$ confirms the $\left(\mathrm{M}^{+}\right)+23$ whereas molecular ion $\left(\mathrm{M}^{+}\right)$for $d i$-benzyl glycerol ether is $272 \mathrm{~m} / z$.

\subsection{Catalyst Characterization}

Primary structures of K-10 supported DTP and cesium exchanged DTP were established by studying their FT-IR absorbance bands over DTP on K-10, bulk unsupported $\mathrm{K}-10$, and $\mathrm{Cs}_{2.5} \mathrm{H}_{0.5} \mathrm{PW}_{12} \mathrm{O}_{40}$ having IR bands at approximately $1080 \mathrm{~cm}^{-1}(\mathrm{P}-\mathrm{O}$ bond in central tetrahedral), $985 \mathrm{~cm}^{-1}$ ( $\mathrm{W}=\mathrm{O}$ terminal bond), $895 \mathrm{~cm}^{-1}$ and $810 \mathrm{~cm}^{-1}$ (W$\mathrm{O}-\mathrm{W}$ bond) related with the asymmetric vibrations of Keggin polyanion [35] (Figure 2). $\mathrm{Cs}_{2.5} \mathrm{H}_{0.5} \mathrm{PW}_{12} \mathrm{O}_{40}$ is characterized by splitting in the $\mathrm{W}=\mathrm{O}$ band, suggesting direct interaction with the poly anion and $\mathrm{Cs}^{+}$cation. FT-IR study of $20 \% w / w$ DTP supported on $\mathrm{K}-10$ and $20 \% w / w \mathrm{Cs}_{2.5} \mathrm{H}_{0.5} \mathrm{PW}_{12} \mathrm{O}_{40} / \mathrm{K}-10$ reveal that the primary Keggin structure remained undistorted in both cases when supported on K-10 clay. When characteristic peaks of bulk heteropoly acid and K-10 clay are overlaid on each other, no shift in the position of the peaks was observed for the supported catalysts. A sharp peak at $1630 \mathrm{~cm}^{-1}$ confirms the presence of $\mathrm{H}_{3} \mathrm{O}^{+}$(Bronsted acidity). Water is bound as water of crystallization in DTP, while in $\mathrm{Cs}_{2.5} \mathrm{H}_{0.5} \mathrm{PW}_{12} \mathrm{O}_{40} / \mathrm{K}-10$ it specifies the presence of partial $\mathrm{H}^{+}$ion attached to the polyanion (- - O-H) and present in $\mathrm{K}-10$ possibly as $\mathrm{H}_{3} \mathrm{O}^{+}$[35].

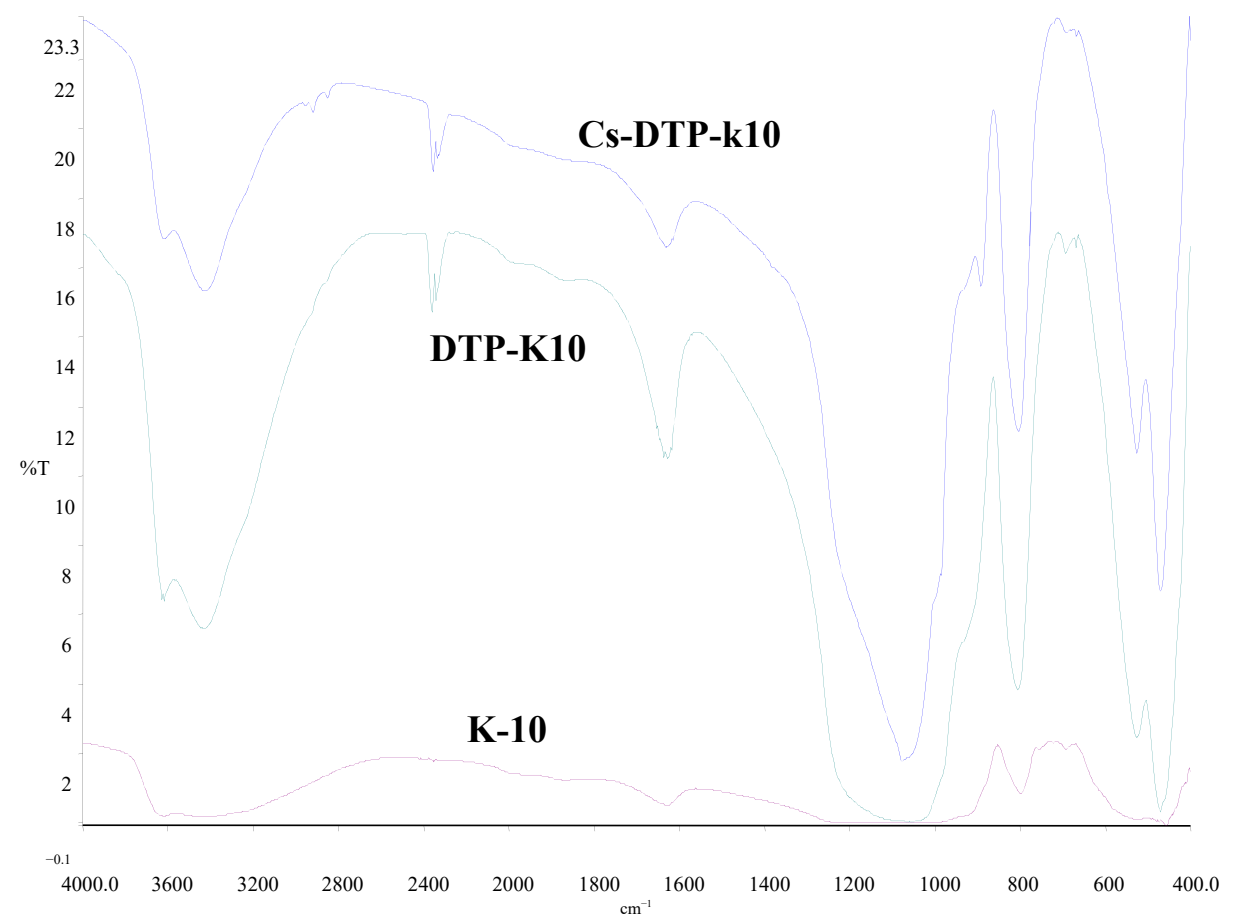

Figure 2. FT-IR patterns of unsupported K-10, bulk DTP on K-10 and 20\% $w / w$ Cs-DTP/K-10.

BET (Brunauer, Emmett and Teller) surface area analysis results of prepared catalysts is presented in Table 1. Surface area of $\mathrm{K}-10$ is $273 \mathrm{~m}^{2} / \mathrm{g}$ which is more than that of 
$\mathrm{Cs}_{2.5} \mathrm{H}_{0.5} \mathrm{PW}_{12} \mathrm{O}_{40} / \mathrm{K}-10\left(239.6 \mathrm{~m}^{2} / \mathrm{g}\right)$. Plots from pore size distribution of these catalysts suggests that the average pore size of catalytic materials is found in the range of 5.0 to $6.5 \mathrm{~nm}$ suggesting that they fall in the mesoporous region of pore size, i.e., $>2 \mathrm{~nm}$. The adsorption-desorption isotherm of DTP/K-10, bulk K-10, and $\mathrm{Cs}_{2.5} \mathrm{H}_{0.5} \mathrm{PW}_{12} \mathrm{O}_{40} / \mathrm{K}-10$ showed that they are of the form of Type IV isotherm type $\mathrm{H}_{3}$ hysteresis loop, a feature of mesoporosity for solid materials. This study also helped to check any morphological changes had occurred in the catalysts after the completion of the reaction. Results in Table 1 show very marginal changes in the surface area, pore volume, and pore diameter of the catalyst after the reaction.

Table 1. Surface area, pore volume and pore diameter analysis.

\begin{tabular}{|c|c|c|c|}
\hline Catalyst & $\begin{array}{c}\text { BET Surface Area } \\
\left(\mathrm{m}^{2} / \mathrm{g}\right)\end{array}$ & Single Point Total Pore Volume $\left(\mathrm{cm}^{3} / \mathrm{g}\right)$ & $\begin{array}{c}\text { Average Pore Diameter } \\
\text { (4A/V by BET) } \\
(\mathrm{nm})\end{array}$ \\
\hline K-10 & $273.01 \pm 0.84$ & 0.392 & 5.749 \\
\hline Fresh Cs-DTP/K-10 & $239.61 \pm 0.45$ & 0.330 & 5.518 \\
\hline Regenerated Cs-DTP/K-10 & $223.49 \pm 0.52$ & 0.308 & 5.558 \\
\hline
\end{tabular}

ICP-MS investigation of the catalyst was conducted to study any chemical changes and leaching (Table 2). Cs content was not detected in the reaction mass proving absence of any leaching of cesium metal whereas amount of tungsten is very small $(0.075 \%)$ as compared with tungsten content in the fresh catalyst and hence negligible. This confirms that there was no leaching of either cesium or tungsten from the catalyst and hence chemical composition of the catalyst remains unchanged. As shown in Figure 3, SEM images of the Cs-DTP/K-10 catalyst before Figure $3 \mathrm{a}$ and after the reaction Figure $3 \mathrm{~b}$ revealed no alteration in the surface morphology of the catalyst after the reaction. In summary, ICPMS and scanning microscope image studies reveal that chemical composition and morphological structure of the catalysts remain intact after the completion of the reaction.

Table 2. ICP-MS Study of the Catalyst.

\begin{tabular}{ccc}
\hline Catalyst & Cs $(\mathbf{p p m})$ & W $(\mathbf{p p m})$ \\
\hline Fresh $\mathrm{Cs}_{2.5} \mathrm{H}_{0.5} \mathrm{PW}_{12} \mathrm{O}_{40} / \mathrm{K}-10$ & 18,999 & 116,708 \\
Metal content in reaction mixture & Undetected & 87.5 \\
\hline
\end{tabular}
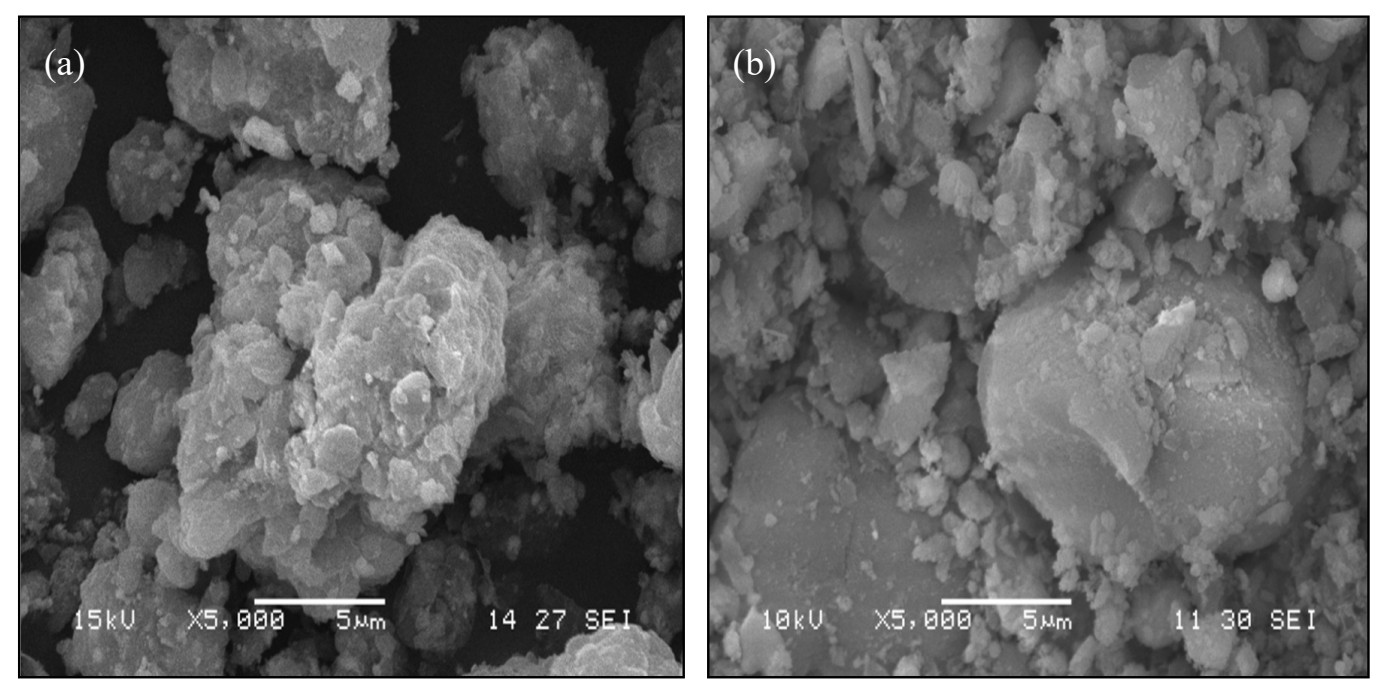

Figure 3. SEM images of (a) fresh Cs-DTP/K-10 catalyst and (b) used Cs-DTP/K-10. 
X-ray diffraction study (Figure 4) of fresh and spent catalyst was conducted after recovering it by filtration post-reaction completion. It was then washed thoroughly with methanol followed by refluxed in methanol to remove the products and un-reacted glycerol from catalyst surface. The catalyst was calcined in furnace at $300{ }^{\circ} \mathrm{C}$. It was observed that there was no crystallographic alteration in structure of the catalyst after the reaction. Keggin structure was observed to be preserved in the step of exchanging of proton of bulk DTP with $\mathrm{Cs}^{+}$ion. The XRD pattern of clay shows a sharp peak at a value of $2 \theta=26.20$, which belongs to quartz. It is also seen that there is no effect on this $2 \theta$ value after exchanging the K-10 clay with either bulk DTP acid or $\mathrm{Cs}^{+}$ion. The amorphous nature of $\mathrm{K}-10$ was confirmed by background XRD reflection for K-10.

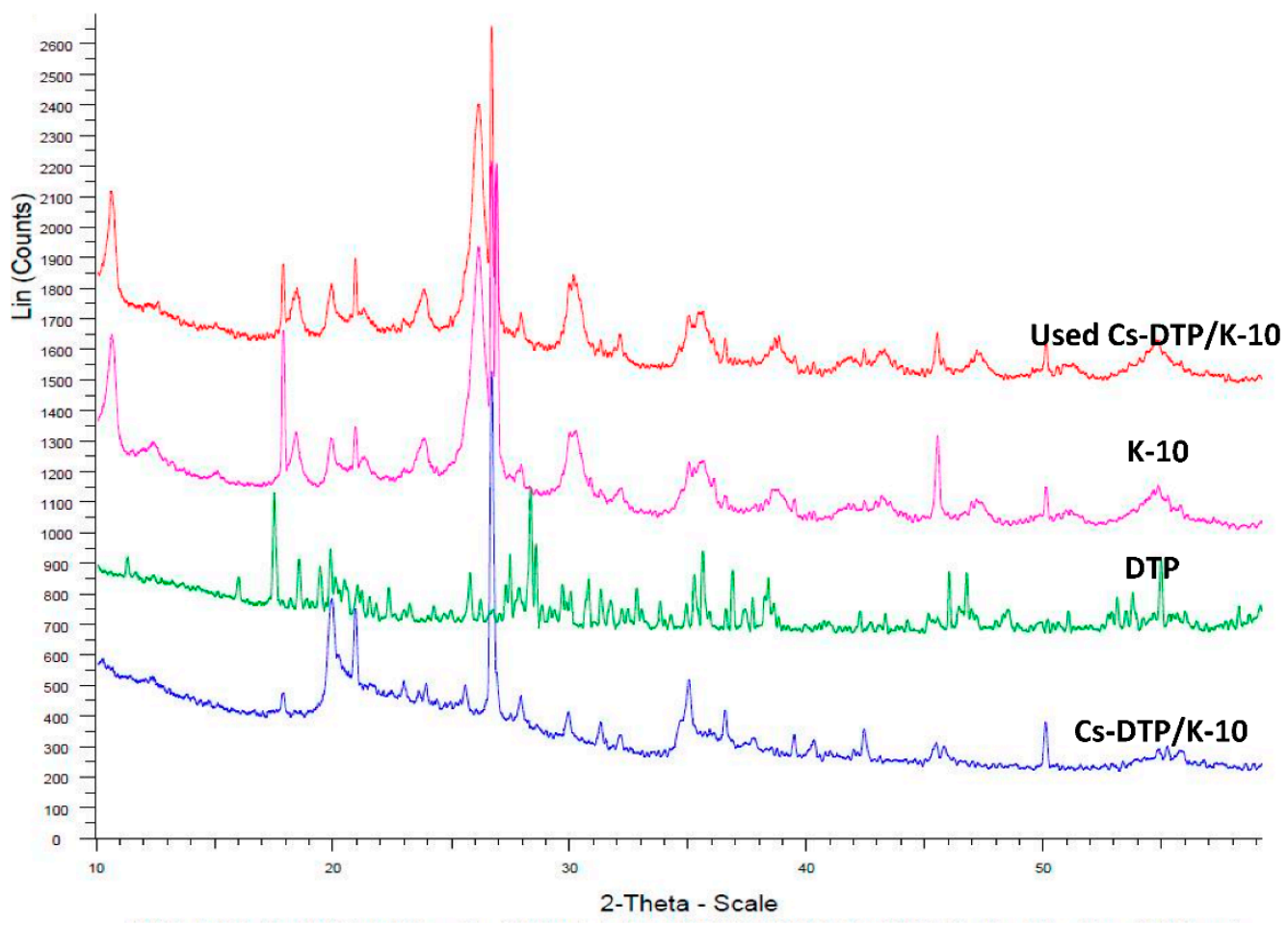

Figure 4. XRD patterns of Cs-DTP/K-10, Bulk DTP, K-10, and used catalyst.

Crystallinity of bulk DTP was seen to be lost while impregnating DTP on K-10. So, the effect of repeated use of catalyst on textural patterns of $\mathrm{Cs}_{2.5} \mathrm{H}_{0.5} \mathrm{PW}_{12} \mathrm{O}_{40} / \mathrm{K}$ 10 was studied by recording the XRD patterns of the reused catalyst vis-à-vis fresh one. No change in crystallinity and textural patterns of the catalyst was observed. This study confirmed the catalyst is stable under the reaction conditions.

\subsection{Parameter Optimization Study}

\subsubsection{Proof of Absence of External Mass Transfer Resistance}

It was necessary to study the effect of external mass transfer resistance on the reaction and therefore effect of agitation on conversion was studied to establish the absence of external resistance. Experiments were conducted in the range between 600 and $1000 \mathrm{rpm}$ with $0.03 \mathrm{~g} / \mathrm{cm}^{3}$ loading of the catalyst at $150{ }^{\circ} \mathrm{C}$. Figure 5 shows that glycerol conversion remained practically the same above $800 \mathrm{rpm}$. Hence, in order to avoid mass transfer resistance, further experiments were carried out at $1000 \mathrm{rpm}$. 


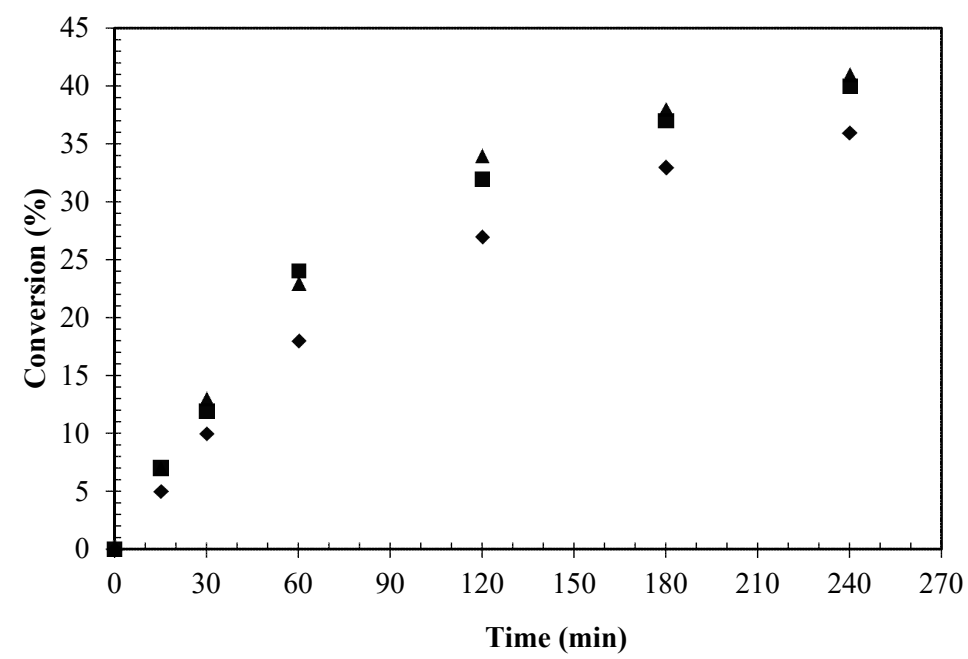

Figure 5. Effect of speed of agitation. Temperature: $150{ }^{\circ} \mathrm{C}$, Catalyst loading: $0.03 \mathrm{~g} / \mathrm{cm}^{3}$, Glycerol:

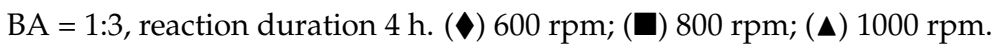

\subsubsection{Effect of Catalyst Loading}

In the absence of any mass transfer resistance, the rate of conversion of glycerol is directly proportional to amount of catalyst used based on the total liquid phase of the reaction mass. Amount of catalyst was varied from $0.01 \mathrm{~g} / \mathrm{cm}^{3}$ to $0.04 \mathrm{gm} / \mathrm{cm}^{3}$ of the reactant. Figure 6 shows that glycerol conversion increases with increased number of active catalytic sites. Conversion remains nearly the same at $3 \% w / v$ onwards. Hence, further parameter optimization was performed at $0.03 \mathrm{~g} / \mathrm{cm}^{3}$ of the catalyst loading.

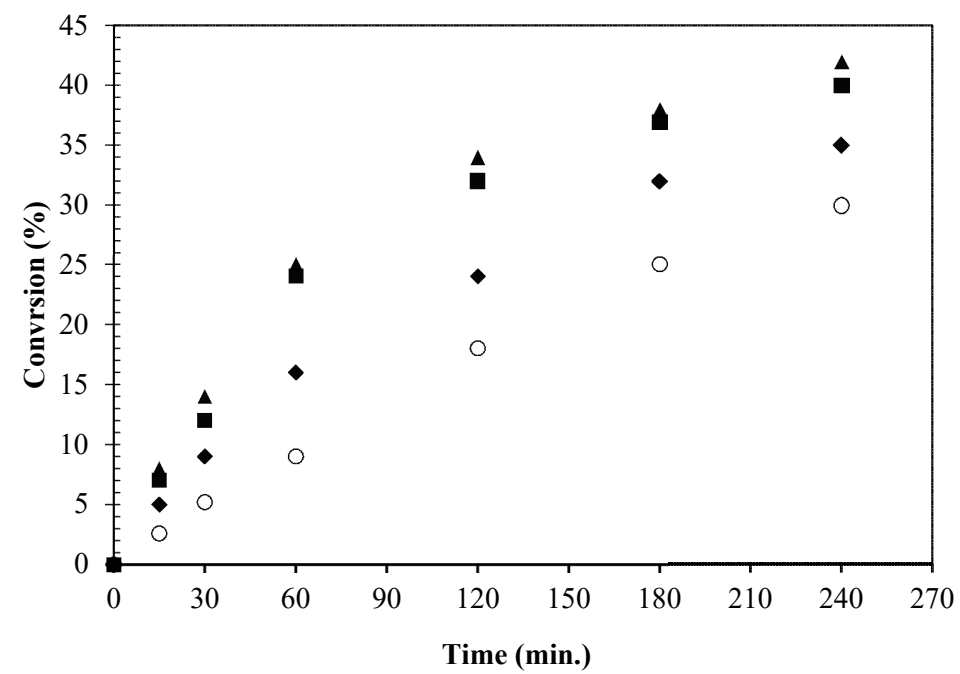

Figure 6. Effect of catalyst loading. Speed of agitation: $1000 \mathrm{rpm}$, temperature: $150{ }^{\circ} \mathrm{C}$, mole ratio Glycerol:BA = 1:3, reaction duration $4 \mathrm{~h}$. (○) $0.01 \mathrm{~g} / \mathrm{cm}^{3} ;(\vee) 0.02 \mathrm{~g} / \mathrm{cm}^{3} ;(\mathbf{\square}) 0.03 \mathrm{~g} / \mathrm{cm}^{3}$; (৯) $0.04 \mathrm{~g} / \mathrm{cm}^{3}$.

\subsubsection{Effect of Mole Ratio of Glycerol to Benzyl Alcohol}

Effect of mole ratio (Figure 7) was studied at glycerol to benzyl alcohol molar ratio in the range of 1:1 to 1:4 with otherwise similar reaction conditions. The conversion of glycerol increased as the benzyl alcohol concentration was found to be increased with respect to glycerol. Although the conversion of glycerol was increased with increased glycerol to benzyl alcohol mole ratio, selectivity towards MBGE decreased while the selectivity of by-product DBE increased, as shown in Figure 8. Therefore, to avoid more DBE formation, a 1:3 glycerol to benzyl alcohol mole ratio was taken for further study. 


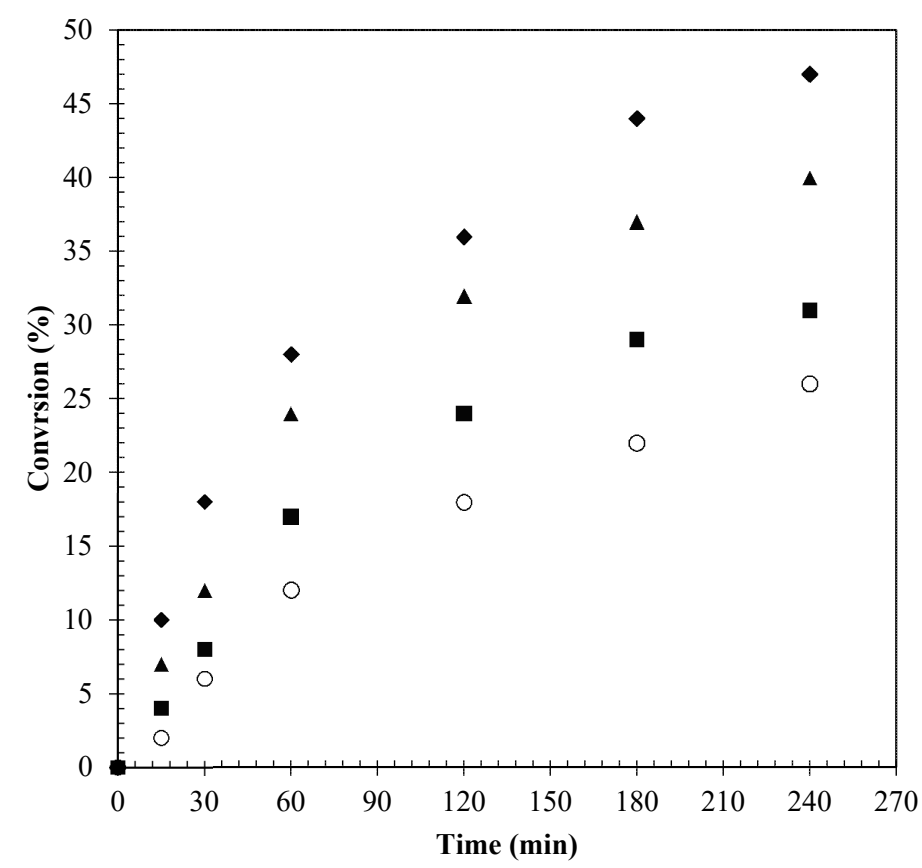

Figure 7. Effect of mole ratio of glycerol to benzyl alcohol. Speed of agitation: $1000 \mathrm{rpm}$, catalyst loading

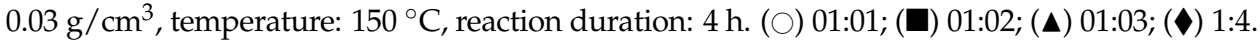

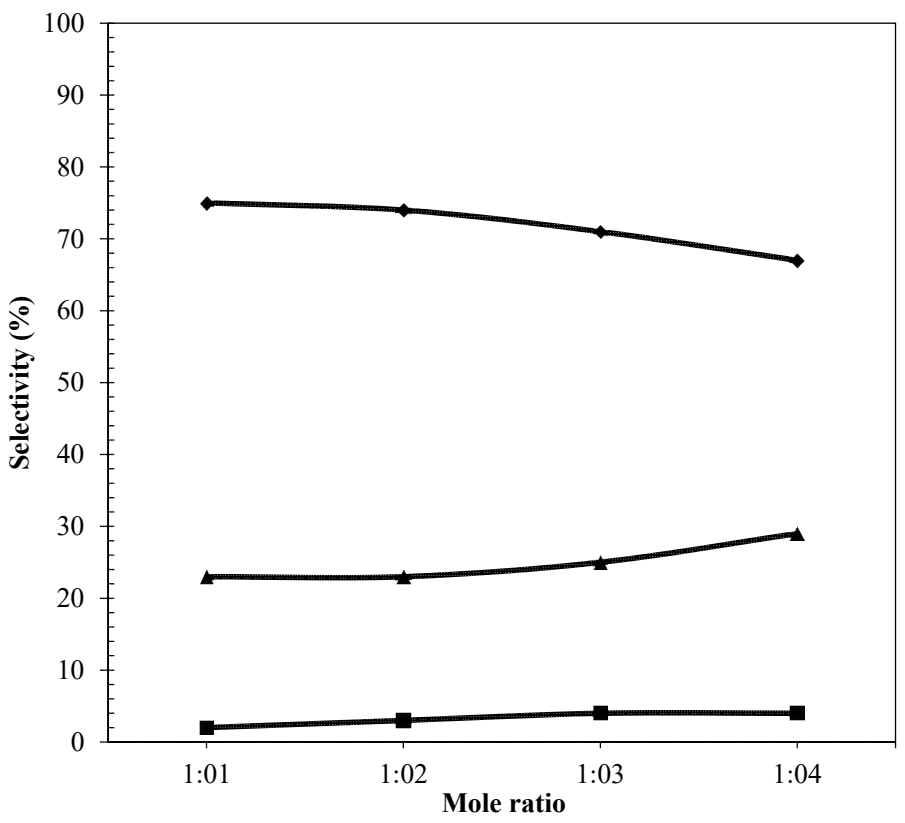

Figure 8. Effect of mole ratio on selectivity. Speed of agitation $1000 \mathrm{rpm}$, temperature $150{ }^{\circ} \mathrm{C}$, catalyst loading $0.03 \mathrm{~g} / \mathrm{cm}^{3}$ reaction duration $4 \mathrm{~h}$. ( ) MBGE; - $)$ DBE; ( ) DBGE.

\subsubsection{Effect of Temperature}

The effect of temperature on conversion of glycerol was studied in the range between 130 and $160{ }^{\circ} \mathrm{C}$. Figure 9 shows that the reaction rate increases with increase in reaction temperature. Above $150{ }^{\circ} \mathrm{C}$, no significant increase in glycerol conversion was observed and therefore $150^{\circ} \mathrm{C}$ was taken as optimum. At higher temperature, intra-particle diffusion resistance was set in. 


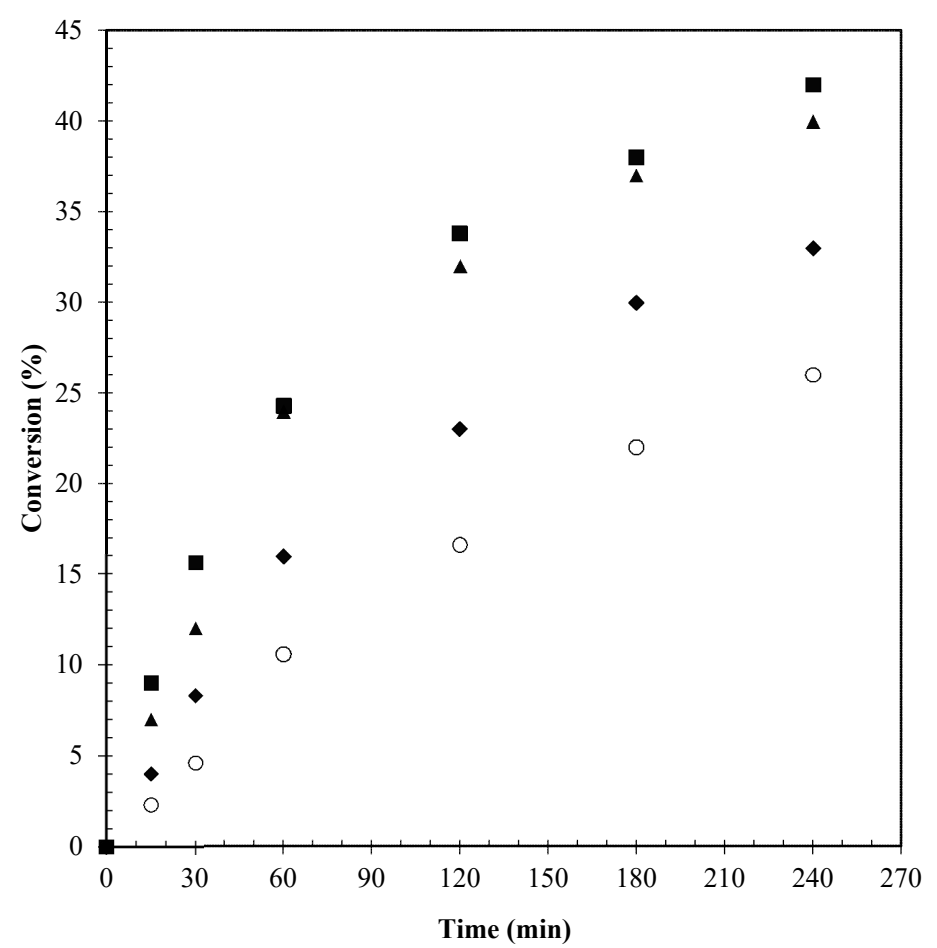

Figure 9. Effect of temperature. Speed of agitation: $1000 \mathrm{rpm}$, Mole ratio Glycerol:BA = 1:3, catalyst loading $0.03 \mathrm{~g} / \mathrm{cm}^{3}$, reaction time $4 \mathrm{~h} .(\bigcirc) 130{ }^{\circ} \mathrm{C} ;(\diamond) 140{ }^{\circ} \mathrm{C} ;(\boldsymbol{\Delta}) 150{ }^{\circ} \mathrm{C} ;(\mathbf{\square}) 160{ }^{\circ} \mathrm{C}$.

\subsection{Reaction Mechanism and Kinetic Model}

Mechanism of this reaction suggests that there are three competing reactions occurring during the benzylation of glycerol. Those reactions as shown in Scheme 2 involve: (i) reaction of in-situ formed benzyl cation with glycerol to from mono-benzyl glycerol ether (MBGE) (ii) reaction of MBGE with another benzyl cation to form di-benzyl glycerol ether (DBGE) and (iii) etherification of benzyl alcohol with another molecule of it to form dibenzyl ether (DBE). The reaction mechanism of $\mathrm{SN}^{2}$ type was suggested with formation of benzyl cation on catalyst surface following a second order rate equation. Camila et al reported that MBGE was the major product formed over $\beta$-zeolite and Amberlyst-35, whereas DBGE was formed in higher yield over K-10 and PTSA, although self-etherification of benzyl alcohol was observed in all the cases [41].

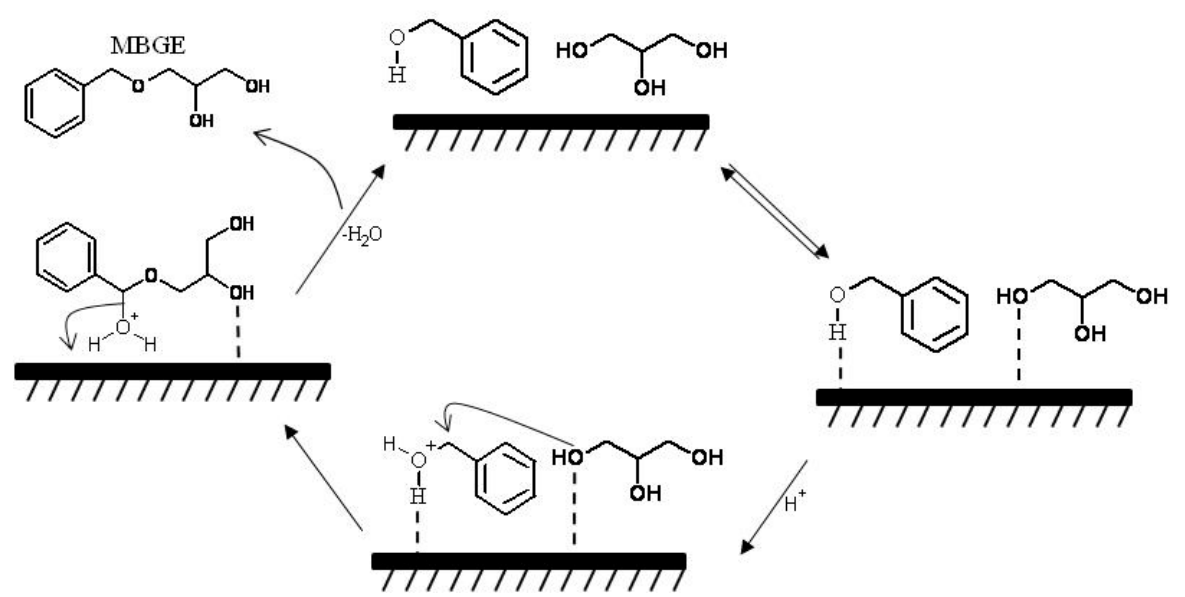

Scheme 2. Reaction mechanism: Benzylation of glycerol.

The kinetic model was deduced based on above results. Understanding mechanism of the etherification reaction is necessary to develop a kinetic model for this reaction. Reaction 
mechanism is assumed to be consisted of; weak adsorption of reactants on surface of the catalyst, reaction occurring on the surface and desorption of product molecules from the surface as shown in Scheme 2.

Weak adsorption of glycerol $(A)$ on a vacant catalyst site $S$ is given by

$$
A+S \stackrel{K_{A}}{\Leftrightarrow} A S
$$

Similarly, the adsorption of benzyl alcohol $(B)$ on the vacant catalyst site is represented as:

$$
B+S \stackrel{K_{B}}{\Leftrightarrow} B S
$$

The surface reaction of $A S$ with $B S$ on the adjacent sites leads to the formation of MBGE (ES) and water (WS) on the catalytic sites

$$
A S+B S \stackrel{K_{2}}{\Leftrightarrow} E S+W S
$$

Desorption of MBGE and water is shown as

$$
\begin{gathered}
E S \stackrel{1 / K_{E}}{\Leftrightarrow} E+S \\
W S \stackrel{1 / K_{W}}{\Leftrightarrow} W+S
\end{gathered}
$$

Now, total concentration of the sites, $C_{t}$ can be expressed as:

$$
C t=C_{S}+C_{A S}+C_{B S}+C_{E S}+C_{W S}
$$

This can also be expressed as:

$$
C t=K_{A} C_{A} C_{S}+K_{B} C_{B} C_{S}+K_{E} C_{E} C_{S}+K_{W} C_{W} C_{S}
$$

Alternatively, the concentration of vacant sites is:

$$
C_{S}=\frac{C_{t}}{\left(1+K_{A} C_{A}+K_{B} C_{B}+K_{E} C_{E}+K_{W} C_{W}\right)} .
$$

Assuming the surface reaction $(C)$ is a rate determining step, then rate of reaction of $A$ is given by,

$$
\begin{gathered}
-r_{A}=-\frac{d C_{A}}{d t}=k_{2} C_{A S} C_{B S}-k_{2}^{\prime} C_{E S} C_{W S} \\
\frac{-d C_{A}}{d t}=\frac{k_{2}\left\{K_{A} K_{B} C_{A} C_{B}-\left(K_{E} K_{W} C_{E} C_{W}\right) / K_{2}\right\} C_{t}^{2}}{\left(1+K_{A} K_{C}+K_{B} C_{B}+K_{E} C_{E}+K_{W} C_{W}\right)^{2}}
\end{gathered}
$$

When the reaction is away from the equilibrium,

$$
\begin{aligned}
-\frac{d C_{A}}{d t} & =\frac{k_{2} C_{t}^{2} K_{A} K_{B} C_{A} C_{B}}{\left(1+\sum K i C i\right)^{2}} \\
& =\frac{k w C_{A} C_{B}}{(1+K i C i)^{2}}
\end{aligned}
$$

where $k w=k_{2} C_{t}^{2} K_{A} K_{B}$ and $w$ is amount of catalyst loading. Assuming that the adsorption constants are very small, then the above equation becomes:

$$
-\frac{d C_{A}}{d t}=k w C_{A} C_{B}
$$


Let $C_{B 0} / C_{A 0}=M$ molar ratio of glycerol to benzyl alcohol at initial time $t=0$. Then, Equation (13) can be expressed in terms of fractional conversion as below:

$$
\frac{d X_{A}}{d t}=k w C_{A 0}\left(1-X_{A}\right)\left(M-X_{A}\right)
$$

up on integration this leads to

$$
\ln \left(\frac{\left(M-X_{A}\right)}{M\left(1-X_{A}\right)}\right)=k_{1}(M-1) t
$$

where $k_{1}=k w C_{A 0}(M-1)$

Thus, from Equation (15) a plot of $\ln \left(\frac{\left(M-X_{A}\right)}{M\left(1-X_{A}\right)}\right)$ Vs $t$ gave a good fit at various reaction temperatures, thereby validating the model (Figure 10). Values of the rate constants at various reaction temperatures were estimated from Figure 10. And Arrhenius plot was used to calculate the apparent energy of activation of the reaction as $18.84 \mathrm{kcal} / \mathrm{mol}$ (Figure 11).

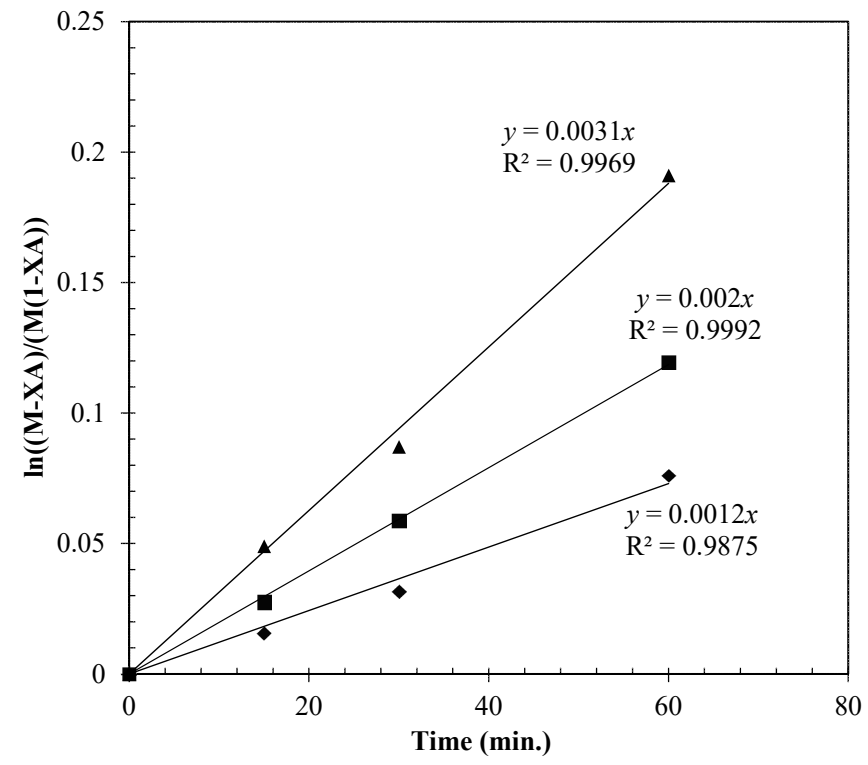

Figure 10. Second order plot. (४) $130{ }^{\circ} \mathrm{C} ;(\boldsymbol{\square}) 140{ }^{\circ} \mathrm{C} ;(\boldsymbol{\Delta}) 150{ }^{\circ} \mathrm{C}$.

\subsection{Catalyst Reusability Study}

Catalyst stability and reusability are of paramount importance during the development of catalyst for new processes. The catalyst was collected, separated, and thoroughly washed thrice by refluxing with methanol for $2 \mathrm{~h}$. Washed catalyst was dried in oven to make it free from moisture and used for the study. Figure 12 shows the activity and selectivity of the catalyst for this reaction. As shown in Figure 12, a slight decrease in glycerol conversion was observed. During this reusability study fresh catalyst was not used to top up in second and third use of the catalyst. Going further, efficacy of catalyst may not show much change for this reaction when switch to vapor phase mode. Based on reaction rate per unit mass of the catalyst, it remains practically the same, which means the catalyst is stable and active. As described in the above sections, results of SEM, surface area measurement and EDAX analysis of the fresh as well as used catalyst showed that the catalyst is stable and there are no structural nor chemical changes having occurred in the catalyst. ICP-MS results showed that there was no leaching of metal in the reaction volume. 


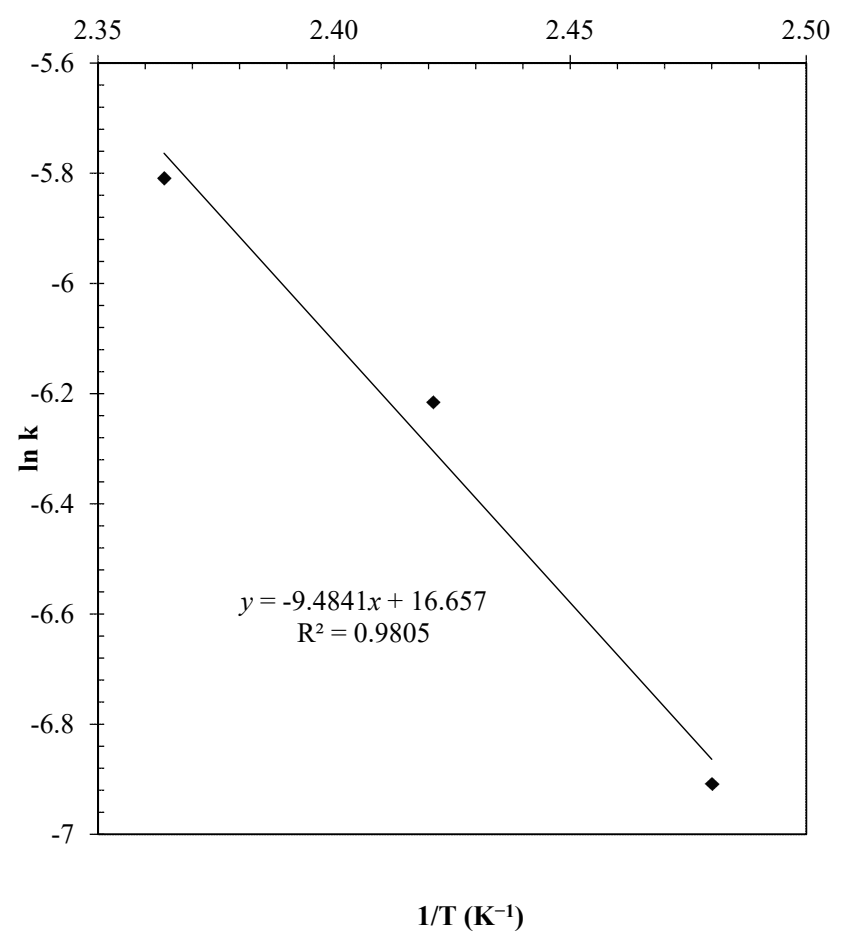

Figure 11. Arrhenius Plot.

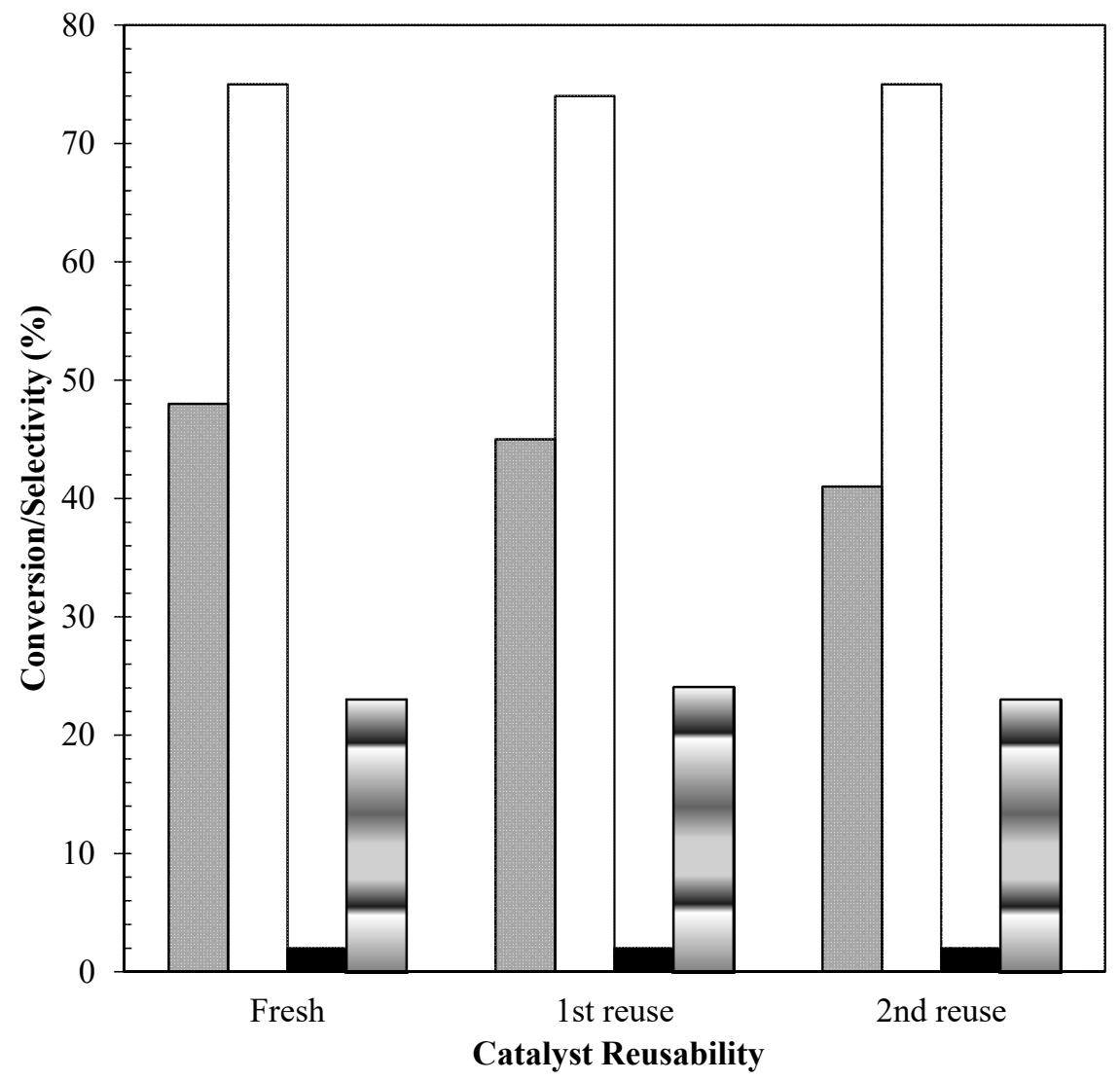

Figure 12. Reusability study. ( $\square$ ) Conversion; ( $\square$ ) MBGE; ( $\square$ ) DBGE; ( $\square$ ) DBE. 


\section{Experimental Section}

\subsection{Chemicals}

All the required chemicals were purchased from well-known firms and used with no further purification. Glycerol was purchased from Merck Ltd., Canada. Benzyl alcohol (99\%); cesium chloride (99.9\%) and hexahydrate dodecatungstophosporic acid (DTP) were purchased from Alfa Acer, Canada. Montmorillonite- K-10 clay was sourced from Fluka, Germany. Methanol was obtained from Merck Ltd., Canada.

\subsection{Catalyst Synthesis}

Cs.2.5 $\mathrm{H}_{0.5} \mathrm{PW}_{12} \mathrm{O}_{40} / \mathrm{K}-10(20 \% w / w)$ catalyst was prepared by a well-developed method in our laboratory and reported elsewhere. It was prepared by using incipient wetness method. Clay was dried at $120^{\circ} \mathrm{C}$ in oven for $3 \mathrm{~h}$ prior to its use. Methanolic solution of $\mathrm{CsCl}$ was $\left(10 \mathrm{~cm}^{3}\right)$ was added to the pre-dried clay. Volume of methanol used was roughly estimated as the pore volume of the clay. This slurry was vigorously stirred at $120^{\circ} \mathrm{C}$ for $1 \mathrm{~h}$. This dried solid material was further treated by impregnation using alcoholic solution of DTP in $10 \mathrm{~cm}^{3}$ methanol and mixed thoroughly and thereafter the solvent was again evaporated by drying in air. It was subjected to calcination for $3 \mathrm{~h}$ at $300{ }^{\circ} \mathrm{C}$. Prior to use, it was oven dried for $3 \mathrm{~h}$.

\subsection{Experimentql Setup}

An autoclave (350 $\mathrm{cm}^{3}$ volume capacity Parr reactor) having a four-bladed pitchedturbine impeller was used to carry out the reactions. Temperature of the reaction was attained using PID controller and kept constant at the accuracy level of $\pm 1{ }^{\circ} \mathrm{C}$ of the set value. The calculated weighed amount of the reactants followed by weighed dried catalyst were placed into the reactor. Heating was started to allow to attain the temperature at the desired value. A zero-hour sample was taken out. Agitation was started. Additional samples were withdrawn at regular time intervals till $4 \mathrm{~h}$ of the reaction time to study the progress of the reaction.

\subsection{Reaction Procedure}

For a typical reaction 0.205 mol glycerol was taken to react with 0.820 mol benzyl alcohol (BA) (1:4 mol ratio, glycerol to BA) with $2.98 \mathrm{~g}$ of fresh catalyst; making $0.03 \mathrm{~g} / \mathrm{cm}^{3}$ of catalyst loading with respect to the total reaction volume. Nitrogen was purged to displace air from the reactor, if any. Experiments were performed at desired values of temperature and speed of agitation with solvent-free conditions.

\subsection{Method of Analysis}

Reaction progress was monitored by taking out clear liquid samples timely after minimizing the speed of agitation of the reaction to zero hence allowing the catalyst to get settle down at the bottom. Analysis of clear samples was carried out using gas chromatography (Agilent Technology, Santa Clara, CA, USA, Model \# 7890 A) equipped with HT Stabilwax capillary thin column $(0.25 \mathrm{~mm}$ i.d $\times 30 \mathrm{~m})$ and flame ionization detector (FID). Being the limiting reactant; conversion of the reaction was calculated based on glycerol. DBGE and MBGE were characterized by mass spectroscopy. Products were separated by column chromatographic extraction using ethyl acetate as solvent.

\subsection{Catalyst Characterization}

\subsubsection{Fourier Transform Infrared Spectroscopy (FTIR)}

FT-IR spectroscopic study of the catalysts were conducted by using Agilent Technology, USA make spectrophotometer. Dried catalyst was mixed with $\mathrm{KBr}$ of spectroscopic grade to prepare thin pellet which were then subjected to several scans before recording the fine spectra. The catalyst was thoroughly characterized during its preparation phase as well as after the reaction. 


\subsubsection{Surface Area Analysis}

Measurement of surface area and porosity of the catalyst was carried out by $\mathrm{N}_{2}$ gas adsorption-desorption technique on ASAP Micromeritics 2010 instrument, USA. Catalysts samples pre-treated under high vacuum for $4 \mathrm{~h}$ at $300^{\circ} \mathrm{C}$ were subjected to BET surface area measurement at $77 \mathrm{~K} . \mathrm{N}_{2}$ adsorption-desorption isotherms of fresh and spent catalysts were deduced by using the conventional BET and BJH (Barrett, Joyner and Halenda) methods.

\subsubsection{Inductively Coupled Plasma Mass Spectroscopy (ICP-MS)}

ICPMS study of the catalyst was carried using model Nexlon 300D, PerkinElmer, USA, to confirm the metal composition of the catalyst and to ensure that no leaching of the metal from catalyst into the reaction mass was observed.

\subsubsection{Scanning Electron Microscopy (SEM)}

SEM images of the catalyst surface were captured using (SU 30 microscope, JEOL, Tokyo, Japan) instrument. Dried catalyst sample was mounted on studs and sputter coated with a thinner film of platinum to make the catalyst surface conducting.

\subsubsection{X-ray Diffraction Study (XRD)}

Bruker AXS powder diffractometer D8 with $\mathrm{Cu}-\mathrm{K} \alpha(1.54 \AA)$ radiation was used to generate XRD patterns to study textural patterns and crystallinity of the catalyst.

\section{Conclusions}

Glycerol benzylation with benzyl alcohol was studied using different catalysts. among which $20 \% w / w$ Cs-DTP/K-10 was the best solid acid catalyst in solvent-free condition with more than $70 \%$ selectivity towards MBGE. MBGE and DBGE are valuable chemicals derived from glycerol and find application as important pharmaceutical intermediates. The effect of reaction parameters on the rate of reaction was studied. Reaction mechanism was discussed; an overall second order rate equation was deduced and validated with $18.84 \mathrm{kcal} / \mathrm{mol}$ as apparent energy of activation. The described reaction is one of the methods to produce valuable chemicals from glycerol. Thorough characterization of the catalyst was carried out to establish that the catalyst is robust and recyclable. It is a green process.

Supplementary Materials: The following are available online at https:/ /www.mdpi.com/2073-4 344/11/1/34/s1, Figure S1: Mass Spectra of mono benzyl glycerol ether. $m / z$ 205, Figure S2: Mass Spectra of dibenzyl glycerol ether.

Author Contributions: The project was concenptualized by G.D.Y. The experiments and characterizations of catalysts were performed by D.P.T. in India and Canada under the supervision of G.D.Y. and A.K.D. The original draft was written by D.P.T. which was discussed and revised by G.D.Y. and A.K.D. Funding and lab facilities were provided by A.K.D. in Canada. All authors have read and agreed to the published version of this manuscript.

Funding: This research was funded by Canada Commonwealth Scholarship and UGC, New Delhi.

Acknowledgments: Devendra P. Tekale gratefully acknowledges the support received from Canadian Commonwealth Scholarship Program (CCSP). G. D. Yadav acknowledges support as R. T. Mody Distinguished Professor, Tata Chemicals Darbari Seth Distinguished Professor of Leader-ship and Innovation, and J. C. Bose National Fellow of Department of Science and Technology, New Delhi (GOI). A. K. Dalai acknowledges Canada Research Chair Program (CRC), Canada.

Conflicts of Interest: The authors declare no conflict of interest. 


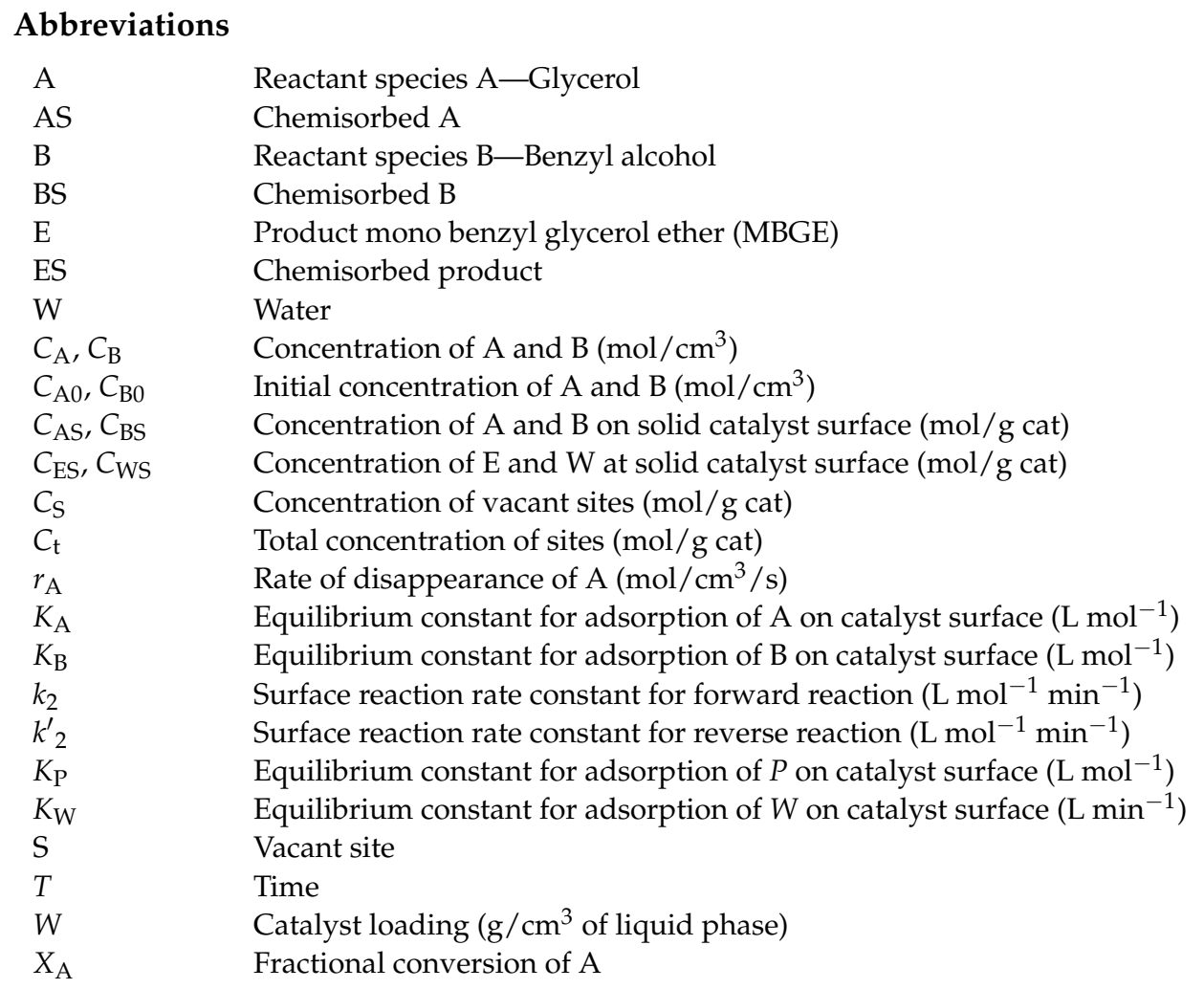

\section{References}

1. Jenck, J.F.; Agterberg, F.; Droescher, M.J. Products and processes for a sustainable chemical industry: A review of achievements and prospects. Green Chem. 2004, 6, 544-556. [CrossRef]

2. He, Q.; McNutt, J.; Wang, J. Utilization of the residual glycerol from biodiesel production for renewable energy generation. Renew. Sustain. Energy Rev. 2017, 71, 63-76. [CrossRef]

3. Jerome, F.; Pouilloux, Y.; Barrault, J. Rational Design of Solid Catalysts for the Selective Use of Glycerol as a Natural Organic Building Block. ChemSusChem 2008, 1, 586-613. [CrossRef] [PubMed]

4. Behr, A.; Eilting, J.; Irawadi, K.; Lwachinski, J.; Linder, F. Improved utilisation of renewable resources: New important derivatives of glycerol. Green Chem. 2008, 10, 13-30. [CrossRef]

5. Behr, A.; Gomes, J.P. The refinement of renewable resources: New important derivatives of fatty acids and glycerol. Eur. J. Lipid Sci. Tech. 2010, 112, 31-50. [CrossRef]

6. Fan, X.; Burton, R.; Zhou, Y. Glycerol (Byproduct of Biodiesel Production) as a Source for Fuels and Chemicals-Mini Review. Open Fuels Energy Sci. J. 2010, 3, 17-22. [CrossRef]

7. Li, S.; Deng, W.; Li, Y.; Zhang, Q.; Wang, Y. Catalytic conversion of cellulose-based biomass and glycerol to lactic acid. J. Energy Chem. 2019, 32, 138-151. [CrossRef]

8. Pagliaro, M.; Ciriminna, R.; Rossi, M.; Pina, C.D. Understanding the glycerol market. Eur. J. Lipid Sci. Technol. 2014, 116, 1432-1439.

9. Samoilov, V.O.; Ramazanov, D.N.; Nekhaev, A.I.; Maximov, A.L.; Bagdasarov, L.N. Heterogeneous catalytic conversion of glycerol to oxygenated fuel additives. Fuel 2016, 172, 310-319. [CrossRef]

10. Koshchii, S.V. Optimization of synthesis of mono-o-methylglycerol isomers. Russ. J. Appl. Chem. 2002, 75, 1434-1437. [CrossRef]

11. Garcia, J.I.; Garcia-Marin, H.; Mayoral, J.A.; Perez, P. Green solvents from glycerol. Synthesis and physico-chemical properties of alkyl glycerol ethers. Green Chem. 2010, 12, 426-434. [CrossRef]

12. Saengarun, C.; Petsom, A.; Tungasmita, D.N. Etherification of Glycerol with Propylene or 1-Butene for Fuel Additives. Sci. World J. 2017, 11. [CrossRef] [PubMed]

13. Linares, N.; Silvestre-Albero, A.M.; Serrano, E.; Silvestre-Albero, J.; Garcia-Martinez, J. Mesoporous materials for clean energy technologies. Chem. Soc. Rev. 2014, 43, 7681-7717. [CrossRef] [PubMed]

14. Klepacova, K.; Mravec, D.; Bajus, M. Etherification of glycerol with tert-butyl alcohol catalysed by ion-exchange resins. Chem. Pap. 2006, 60, 224-230. [CrossRef]

15. da Machado, M.S.; Sastre, E.; Perez-Pariente, J.; Cardoso, D.; De Guerenu, A.M. Selective synthesis of glycerol monolaurate with zeolitic molecular sieves. Appl. Catal. A Gen. 2000, 203, 321-328. [CrossRef]

16. Dominguez, C.M.; Romero, A.; Santos, A. Improved Etherification of Glycerol with Tert-Butyl Alcohol by the Addition of Dibutyl Ether as Solvent. Catalysts 2019, 9, 378. [CrossRef]

17. Gu, Y.; Azzouzi, A.; Pouilloux, Y.; Jerome, F.; Barrault, J. Heterogeneously catalyzed etherification of glycerol: New pathways for transformation of glycerol to more valuable chemicals. Green Chem. 2008, 10, 164-167. [CrossRef] 
18. Barrault, J.; Jerome, F. Design of new solid catalysts for the selective conversion of glycerol. Eur. J. Lipid Sci. Technol. 2008, 110, 825-830. [CrossRef]

19. Fahrenholtz, K.E. Adrenergic Blocking Agents. U.S. Patent No. 4,304,721, 8 December 1981.

20. Kaminuma, M. Skin Preparation Composition for External Use. U.S. Patent No. 0,257,436 A1, 16 November 2006.

21. Yadav, G.D.; Goel, P.K.; Joshi, A.V. Alkylation of dihydroxybenzenes and anisole with methyl-tert-butyl ether (MTBE) over solid acid catalysts. Green Chem. 2001, 3, 92-99. [CrossRef]

22. Yadav, G.D.; Doshi, N.S. Alkylation of hydroquinone with methyl-tert-butyl-ether and tert-butanol. Catal. Today 2000, 60, 263-273. [CrossRef]

23. Verhoef, J.M.; Kooyman, J.P.; Peters, A.J.; van Bekkum, H. A study on the stability of MCM-41-supported heteropoly acids under liquid- and gas-phase esterification conditions. Microporous Mesoporous Mater. 1999, 27, 365-371. [CrossRef]

24. Chu, W.; Yang, X.; Ye, X.; Wu, Y. Vapor phase esterification catalyzed by immobilized dodecatungstosilicic acid (SiW12) on activated carbon. Appl. Catal. A Gen. 1996, 145, 125-140. [CrossRef]

25. Yadav, G.D. Synergism of clay and heteropoly acids as nano-catalysts for the development of green processes with potential industrial applications. Catal. Sury. Asia 2005, 9, 117-137. [CrossRef]

26. Yadav, G.D.; Nair, J.J. Sulfated zirconia and its modified versions as promising catalysts for industrial processes. Microporous Mesoporous Mater. 1999, 33, 1. [CrossRef]

27. Yadav, G.D.; Nair, J.J. Isomerisation of citronellal to isopulegol using shape selective catalysts UDCaT-2. Langmuir 2000, 16, 4072. [CrossRef]

28. Yadav, G.D.; Murkute, A.D. Novel efficient mesoporous solid acid catalyst UDCaT-4: Dehydration of 2-propanol and alkylation of mesitylene. Langmuir 2004, 20, 11607-11619. [CrossRef]

29. Yadav, G.D.; Sengupta, S. Friedel-Craft's alkylation of diphenyl oxide with benzyl chloride over sulphated zirconia. Org. Proc. Res. Devel. 2002, 6, 256-262. [CrossRef]

30. Yadav, G.D.; Kamble, S.B. Atom efficient Friedel-Crafts acylation of toluene with propionic anhydride over solid mesoporous superacid UDCaT-5. Appl. Catal. A Gen. 2012, 433, 265-274. [CrossRef]

31. Malkar, R.S.; Yadav, G.D. Selectivity engineering in synthesis of thymol using sulfated $\mathrm{ZrO}_{2}-\mathrm{TiO}_{2}$. Ind. Eng. Chem. Res. 2017, 56, 8437-8447. [CrossRef]

32. Tiwari, M.S.; Yadav, G.D. Novel aluminium exchanged dodecatungstophosphoric acid supported on K-10 clay as catalyst: Benzoylation of diphenyloxide with benzoic anhydride. RSC Adv. 2016, 6, 49091-49100. [CrossRef]

33. Wagh, D.P.; Yadav, G.D. Multi-functional Fe-A10.66DTP/MCF catalyst in cascade engineered synthesis of the drug butamben: Novelty of catalyst, reaction kinetics and mechanism. Mol. Catal. 2020, 483, 110711. [CrossRef]

34. Yadav, G.D.; Salgaonkar, S.S.; Asthana, N.S. Selectivity engineering in isopropylation of benzene to cumene over cesium substituted dodecatungstophoshoric acid on K-10 clay. Appl. Catal. A Gen. 2004, 265, 153-159. [CrossRef]

35. Yadav, G.D.; Asthana, N.S.; Kamble, V.S. Friedel-Crafts benzoylation of p-xylene over clay supported catalysts: Novelty of cesium substituted dodecatungstophosphoric acid on K-10 clay. Appl. Catal. A Gen. 2003, 240, 53-69. [CrossRef]

36. Yadav, G.D.; Surve, P.S. Regioselective ring opening reaction of epichlorohydrin with acetic acid to 3-chloro-2-hydroxypropyl acetate over cesium modified heteropolyacid on clay support. Appl. Catal. A Gen. 2013, 468, 112-119. [CrossRef]

37. Yadav, G.D.; George, G. Monoalkylation of biphenyl over modified heteropoly acids: Novelty of cesium substituted dodecatungstophosphoric acid supported on hexagonal mesoporous silica. Catal. Today 2009, 141, 130-137. [CrossRef]

38. Tiwari, M.S.; Yadav, G.D. Kinetics of Friedel-Crafts benzoylation of veratrole with benzoic anhydride using Cs2.5H0.5PW12O40/K10 solid acid catalyst. Chem. Eng. J. 2015, 266, 64-73. [CrossRef]

39. Tekale, P.T.; Yadav, G.D. Esterification of propanoic acid with 1,2-propanediol: Catalysis by cesium exchanged heteropoly acid on K-10 clay and kinetic modelling. React. Chem. Eng. 2021. [CrossRef]

40. Yadav, G.D.; Goel, P.K. Selective synthesis of perfumery grade cyclohexyl esters from cyclohexene and carboxylic acids over ion exchange resins: An example of 100\% atom economy. Green Chem. 2000, 2, 71-77. [CrossRef]

41. Silva Camila, R.B.; Goncalves Valter, L.C.; Lachter, E.R.; Mota, C.J.A. Etherification of glycerol with benzyl alcohol catalyzed by solid acids. J. Braz. Chem. Soc. 2009, 20, 201-204. [CrossRef] 